\title{
O Livro da Virtuosa Benfeitoria, os Espelhos de Príncipes e o ideal de governo renascentista na Dinastia de Avis (1385-1580)
}

The Book of Virtuous Wisom, the Mirror of Princes and the ideal of renaissance government of the

\author{
House of Avis (1385-1580)
}

El Libro de la Virtuosa Benfeitoria, los Espejos de Príncipes y el ideal del gobierno renacentista en la Casa de Avis (1385-1580)

Recebido: 15/01/2021 | Revisado: 18/01/2021 | Aceito: 19/01/2021 | Publicado: 24/01/2021

\author{
Amanda Malheiros Pereira \\ ORCID: https://orcid.org/0000-0003-0462-1093 \\ Universidade Estadual de Maringá, Brasil \\ E-mail: amandamalheiros@outlook.com \\ Célio Juvenal Costa \\ ORCID: https://orcid.org/0000-0003-1226-7805 \\ Universidade Estadual de Maringá, Brasil \\ E-mail: celiojuvenalcosta@gmail.com
}

\begin{abstract}
Resumo
O nosso intuito é de examinar, por meio da análise do Livro da Virtuosa Benfeitoria de D. Pedro (1392 - 1449), como o gênero dos Espelhos de Príncipes se apresentou em Portugal no contexto da Dinastia de Avis (1385-1580), ao projetar um governante ideal. Tendo em vista o século XV como o período em que as ideias renascentistas italianas inspiradas na antiguidade clássica começam a adentrar a corte portuguesa, com a introdução de obras de caráter cívico e pedagógico, organizamos o texto no sentido de compreender as características presentes nesse tratado para a valorização das capacidades do ser humano, sobretudo no campo da Educação. Para realizar tal investigação, a metodologia parte dos pressupostos da pesquisa bibliográfica e documental, recorrendo aos aportes da História Social. resumo.
\end{abstract}

Palavras-chave: Dinastia de Avis; Espelhos de príncipes; História da Educação; Portugal.

\begin{abstract}
Our intention is to examine, through the analysis of the Book of Virtuous Wisom of D. Pedro (1392-1449), how the genre of the Mirrors of Princes appeared in Portugal in the context of the House of Avis (1385-1580), when designing an ideal ruler. In view of the 15th century as the period in which the ideas of the Italian Renaissance inspired by classical antiquity began to enter the Portuguese court, with the introduction of works of a civic and pedagogical nature, we organize the text to understand the characteristics present in this treaty of the valorization of human capacities, especially in the field of Education. To carry out this research, the methodology starts from the assumptions of bibliographic and documentary research, using the contributions of Social History.
\end{abstract}

Keywords: House of Avis; Mirror of princes; History of Education; Portugal.

\section{Resumen}

Nuestra intención es examinar, a través del análisis del Libro de la Virtuosa Benfeitoria de D. Pedro (1392-1449), cómo apareció en Portugal el género de los Espejos de los Príncipes en el contexto de la Casa de Avis (1385-1580), al diseñar un gobernante ideal. En vista del siglo XV como el período en el que las ideas del Renacimiento italiano inspiradas en la antigüedad clásica comenzaron a ingresar a la corte portuguesa, con la introducción de obras de carácter cívico y pedagógico, organizamos el texto para comprender las características presentes en este tratado de la valorización de las capacidades humanas, especialmente en el campo de la Educación. Para llevar a cabo dicha investigación, la metodología parte de los supuestos de la investigación bibliográfica y documental, utilizando los aportes de la Historia Social.

Palabras clave: Casa de Avis; Espejos de príncipes; Historia de lá Educación; Portugal.

\section{Introdução}

Analisaremos neste artigo, como gênero de Espelhos de Príncipes se apresentou em Portugal, em especial, suas características projetadas no Livro da Virtuosa Benfeitoria, o que tornou o tratado o primeiro de seu gênero em Portugal. De forma geral, os Espelhos eram espécies de manuais que orientavam a educação dos príncipes para o bom governo, combinando 
elementos de origens diversas, os quais veremos ao longo do texto. Nossa fonte pertente ao período do século XV, mais precisamente vinculada ao contexto da Dinastia de Avis (1385-1580) ${ }^{1}$, momento onde as ideias renascentistas italianas inspiradas na antiguidade clássica começam a adentrar na corte portuguesa, introduzindo obras de caráter cívico e pedagógico. O autor, D. Pedro (1392- 1449) $1 .^{\circ}$ Duque de Coimbra, foi um infante da dinastia de Avis, filho do rei João I e de Filipa de Lencastre.

Ao longo da Baixa Idade Média (XI-XV), a importância da construção da imagem de um rei sábio e virtuoso se faz presente nos escritos políticos do período, tornando a reflexão acerca do exercício da monarquia um dos aspectos relevantes ao ofício real. (Le Goff, 1994). Ao estabelecer um diálogo com as fontes, entendemos que compreender o modelo de príncipe cristão existente no imaginário medieval, requer também uma análise do contexto histórico em que se encontra o tratado que pretendemos estudar, tendo em vista que o príncipe deve conduzir seus súditos com exemplos de virtudes e de atitudes morais difundidas pela Igreja Católica.

De acordo com Michel Senellart, em seu livro As artes de governar, $\mathrm{o}$ ator de reinar, no contexto medieval, correspondia ao exercício de guiar os homens para além do cumprimento de seus deveres terrenos, e sim para o governo das almas, visando a salvação do espírito. Sendo assim, podemos conceber a ideia de governo no século XV como uma arte, em que sua ciência seria conduzir o ser humano para a glória de Deus. (Senellart, 2006, p.27).

Em meio às dificuldades devido às visíveis transformações sociais e econômicas, engendradas pela sucessiva substituição do valor estável da terra por uma economia de mercado, emergem doutrinas que defendem as bases democráticas de um governo monárquico. Ultrapassada a luta entre poderes temporal e espiritual do século XIV, a atitude regalista coordenada pelo direito romano assume a cena, bem como a secularização subsequente. (Soares, 1993)

Estruturada segundo o modelo da hierarquia eclesiástica, a sociedade portuguesa passa por uma renovação nos vários campos da cultura, que pretende garantir e consolidar a consciência nacional, ao atender os requisitos do mundo civilizado revelado. O eclodir de um novo tempo carrega consigo um enorme interesse pela educação junto do desenvolvimento de uma sociedade renovada. Tal anseio levará à tradução de autores clássicos, prenunciando o humanismo e, consequentemente, a gradual laicização do Estado e, dessa forma, convergindo cada vez mais para a evolução do conceito de Estado e a função do governante. (Soares, 1993, p.295).

Os pensadores dos finais da Idade Média, por meio de reflexões a respeito do novo quadro europeu que se configurava, em que se sobressai o crescimento da força e importância dos estados, incorporam a consolidação de um sentimento nacional monárquico, que encontra uma explicação na fidelidade a um certo ideal de rei. É nesse cenário que se tem a necessidade de tratados, dotados de uma ética cristã e funcionalismo laico. Tais tratados são dirigidos não só a príncipes, mas também imperadores, reis e detentores do poder senhorial. (Soares, 1993).

Tal produção se inscreve no chamado gênero literário que trata dos Espelhos de Príncipes. Levando em consideração sua tradição medieval, os Espelhos são tratados políticos redigidos sob a perspectiva cristã, onde observamos, com o passar dos séculos, a incorporação dos componentes culturais de vertente bíblica com modelos da antiguidade clássica, como reis e filósofos. Assim, é possível estabelecer uma relação entre a construção de um governante ideal, juntamente com a compreensão da sociedade política do período estudado.

\section{Metodologia}

\footnotetext{
${ }^{1}$ A coroação de D. João I deu início a uma nova dinastia em Portugal, a dinastia de Avis (1385-1580), que consolidou a independência de Portugal em relação ao Reino de Castela colocando fim a uma das crises sucessórias experimentadas pelo reino português.
} 
Nossa pesquisa qualitativa, ao revisitar a historiografia sobre o tema abordado, ou seja, alguns textos que tratam sobre Portugal e suas peculiaridades, aliado com outros sobre a tradição dos Espelhos ao longo dos séculos, nos possibilitou perceber sob a abordagem da História Social, as motivações, transformações e consequências empreendidas pelas pessoas ao longo do tempo. Ao utilizar o viés teórico da perspectiva da longa duração, proposta por Fernand Braudel (1990), há a necessidade, de maneira geral, que os questionamentos do presente remetam ao passado, ao se objetivar uma maior compreensão do sujeito como um todo, assim, também, como abrangência geral, o todo que envolve este indivíduo.

Para realizar tal investigação, nosso método parte dos pressupostos da pesquisa bibliográfica e documental, recorrendo aos aportes da História da Educação. Para Marc Bloch (2001) e Carlo Ginzburg (1991) o historiador tem a peculiaridade de ir em direção ao passado motivado por interesses e problemas do seu próprio tempo, lidando com fatos, fenômenos e pessoas de outras épocas. Desta forma, ao investigarmos o retrospecto do gênero dos Espelhos, juntamente das análises do cenário português, entendemos que poderemos entender com maior clareza as relações em nosso atual contexto, pretendendo colaborar com as pesquisas na área da História da Educação.

Com o aporte do texto de Pereira et al. (2018), sobre a metodologia da pesquisa científica, nos atentando para o capítulo que analisa a ciência na história do conhecimento humano, encontramos algumas definições fundamentais para redigir nosso texto. A reflexão a respeito das importâncias e relevâncias de nossos estudos se embasa na relação que os variados tipos de conhecimento: o uso da intuição, experimentação e racionalização, estabelecem pelo intermédio dos sentidos e do meio em que o homem se encontra. O conhecimento passa, dessa forma, da percepção e consciência para também um utilitário na resolução de problemas.

A solução de um problema proposta pelo conhecimento, perpassa os campos da idealização, do pensamento, da memorização, da reflexão e da criação. Ao acompanhar parâmetros cronológicos da consciência, o saber varia em intensidade de forma dinâmica e inacabada, servindo de referencial para pesquisas qualitativas e quantitativas das relações sociais. Assumindo a curiosidade e o desejo inatos do ser em relação ao saber, no ato de conhecer, o indivíduo atravessa a realidade e age sobre os fatos, interferindo, experimentando e reorganizando suas informações, o que permite mudanças no todo e em si mesmo. (Pereira, 2018, p.14-15)

Após nossa análise, compreendemos que por meio das ideias, opiniões e teorias levantadas sobre diferentes temas e subtemas, sistematizados e organizados em diferentes categorias de obras científicas, tais como livros; monografias e dissertações, podemos elaborar novos estudos, partindo de diferentes perspectivas e novas indagações, que podem nos direcionar para diferentes encaminhamentos. Ao considerar os questionamentos do presente que nos sugerem o retorno a investigação de cenários passados, percebemos de que maneira nossa memória se constitui, esquadrinhando exemplos para que possamos pretender e manifestar soluções atuais.

Ao entender o artigo científico como um documento que apresenta revisões de literaturas, constituído de textos da atualidade, sucedido por argumentos e visando uma contenção de informações de maneira simplificada, necessárias ao entendimento, essa pesquisa tem o intuito de permitir o acesso a outros pesquisadores e demais leitores interessados no assunto, para que se atualizem e construam novos conhecimentos. (Pereira, 2018, p.36-37)

\section{O Gênero dos Espelhos de Príncipes}

Os medievais constatavam os Espelhos de Príncipes como uma metáfora, onde o emprego da palavra espelho configurava um meio pelo qual se conferia a ideia de reflexo, no sentido de que, ao olharmos para um espelho, vemos a projeção de nossa própria imagem refletida. Dito isso, a significação do termo utilizado neste artigo: 
Espelho, do latim, speculum, denota a reprodução fiel da imagem, representação, reflexo. Em seu sentido figurado, um modelo, exemplo a ser seguido, imitado. Deriva do verbo depoente latino speculor, cuja primeira acepção é observar. (Costa, 2004, p. 186 - grifos do autor)

As instruções contidas nos Espelhos de Príncipes manifestam um ensinamento político que recolhem um conjunto de valores morais sob os quais o príncipe deve estabelecer para si mesmo, e tomar como fonte de aprendizagem e referencial condutor no ato de governar, tanto a si próprio quanto na arte de governar seus súditos. (Haroche, 1998).

Esse gênero da literatura medieval, escrito na maioria das vezes por pessoas ligadas à Igreja Católica, é uma espécie de manual que busca, de maneira didática, instruir o príncipe nas artes de governar. Também conhecidos como "tratados", esse tipo de literatura visava orientar o príncipe em como se comportar nas mais variadas situações quando este estivesse no comando do reino. Seja em relação aos seus súditos, aos conselheiros do governante, à guerra, à cidade, à coisa pública, ou a outros ofícios do Estado real.

Os escritos dos Espelhos, apesar das características próprias de acordo com o local e o contexto político em que foram elaborados, buscavam, na maioria das vezes, exemplos de príncipes, virtudes e experiências nos clássicos antigos, como filósofos da Grécia Antiga, intelectuais do Império Romano ou até mesmo por meio de exemplos de reis e conquistadores que obtiveram grande prestígio em seu governo. Aparecem também nos tratados, trechos e passagens bíblicas e seus personagens como referência de conduta e modo de vida, além de figuras relevantes do clero com passagens inspiradoras e virtuosas.

No decorrer da Idade Média, as virtudes variam de importância. Desde os primeiros séculos da cristandade, com a patrística $^{2}$ por exemplo, temos a presença da Bíblia e do mundo clássico. Baseado nas ideias platônicas de mundo sensível e inteligível, ao adequar a noção da razão, que se eleva para uma alma iluminada, A cidade de Deus ${ }^{3}$ separa a cidade mundana da divina, passando a contar a trajetória da humanidade em gerações. Mais tarde, com a escolástica, introduz-se as ideias aristotélicas na tentativa de adequar razão e fé, desafio dos teólogos da Igreja, ao aliar as questões divinas com os saberes clássicos, idealizando um rei político. De acordo com Costa (2003), foi com os carolíngios, no século IX, que os ideais de justiça, sabedoria, fortaleza, prudência, misericórdia e clemência foram introduzidos definitivamente no caráter político pedagógico dos tratados, colocando o rei como um dirigente inspirador e instrutor de seu povo.

David Nogales Rincon, em seu texto Los espejos de príncipes en castilla (Siglos XIII-XV): Un modelo literario de la realeza bajomedieval, nos ajuda a compreender que, dos séculos XIII ao XV, a Idade Média usufruiu de grande bibliografia do gênero dos espelhos. A presença dos tratados em bibliotecas da nobreza também demonstra uma pretensão da tipologia para além da educação do príncipe, como guias gerais de comportamento. Afinal, alguns desses manuais possuíam conselhos que se estendiam também aos cortesãos e conselheiros. (Rincon, 2006, p.11)

Conforme Fábio André Hahn, em seu artigo Reflexos da perfeição: alguns elementos do gênero espelhos de príncipe na Idade Moderna, é justamente a partir do século XV que foram escritas obras no sentido de instruir não só os príncipes, mas também conselheiros e juízes. Destacam-se nesse modelo obras como O Perfeito Cortesão, de Diomede Carafa ${ }^{4}$, considerada

\footnotetext{
${ }^{2}$ Patrística é o termo que designa, de forma genérica, a filosofia cristã nos primeiros séculos logo após o seu surgimento, ou seja, a filosofia dos padres (pais) da Igreja. A patrística surge quando o cristianismo se difunde e se consolida como religião de importância social e política, e a Igreja se firma como instituição, formulando-se então a base filosófica da doutrina cristã, especialmente na medida em que ela se opõe ao paganismo e às heresias que ameaçavam sua própria unidade interna. Predominam assim os textos apologéticos, em defesa do cristianismo. A patrística representa a síntese da filosofia grega clássica com a religião cristã, tendo seu início com a escola de Alexandria, que revela um pensamento influenciado pelo espiritualismo neoplatônico e pela doutrina ética do estoicismo (JAPIASSÚ; MARCONDES, 2001, p. 148).

${ }^{3}$ Para Le Goff, Santo Agostinho (354-430), em A cidade de Deus foi quem escreveu o que viria a ser considerado o primeiro Espelho de Príncipe cristão. Nessa obra, ele exalta as virtudes como um espelho da doutrina cristã. Daí a ideia de espelho, como a pretensão de fazer acontecer na terra o reflexo que busca a perfeição divina. (Costa, 2003)

${ }^{4}$ Diomede Carafa (1406 - 1487) foi um político italiano, além de redigir conselhos para cortesãos, dirigiu na década de 1480 a Fernando de Nápoles um memorando sobre O ofício de um bom príncipe. (SKINNER, 1999, p.128)
} 
como uma das precursoras dessa peculiaridade, e outro escrito de 1513-1518 bastante considerável é O Cortesão de Baldassare Castiglione $^{5}$. (Hahn, 2006)

É no século XV, inclusive, que teremos a incorporação massiva das fontes clássicas, devido ao contato com a literatura cristã que se apropria de autores como Platão, Aristóteles, Virgílio ${ }^{6}$, Ovídio ${ }^{7}$, Terêncio $^{8}$ e Cícero ${ }^{9}$. Aparecem, também, recorrentemente, São Tomás de Aquino, Boécio ${ }^{10}$, Lactancio $^{11}$, Sêneca ${ }^{12}$ e Horácio ${ }^{13}$. A dinâmica se desenvolve num esquema expositivo que aborda a educação do príncipe desde o uso da poesia até a forma dialógica, incorporando novos campos da ética, como a educação física do príncipe e instrução de aspectos relacionados diretamente com a pedagogia. (Rincon, 2006, p.17)

Ao analisar os tratados, podemos observar que a tipologia que trata dos espelhos, possui uma certa manutenção de seus elementos, mesmo com a mudança de contexto e por vezes alterações na aplicabilidade. Vemos a frequência no uso de fontes clássicas, no Direito Romano, no emprego de grandes personagens históricos e bíblicos, além de passagens da Sagrada Escritura. A presença de exemplos ao longo dos tratados, denota um caráter didático da instrução principesca, utilizando de virtudes morais e religiosas.

Dessa forma, podemos conceber os Espelhos de Príncipes medievais como gêneros literários que tinham por objetivo a formação de príncipes/reis virtuosos, tendo em vista que, por meio de uma formação virtuosa, o governante viesse a exercer seu papel, enquanto dirigente de um povo que age de forma assertiva e correta. Ao longo da história, vemos como esses escritos políticos influenciaram a formação de grandes homens de poder e até mesmo pessoas comuns.

O gênero Espelhos de Príncipes se fez presente, também, na Península Ibérica em geral e, claro, no reino lusitano também. É o que trataremos na sequência.

\section{A Dinastia de Avis e o Renascimento Português}

De acordo com a historiadora Adeline Rucquoi (1995), a Península Ibérica situa-se no próprio coração do mundo medieval na medida em que sua herança latina do Império Romano permanece viva graças à unificação visigótica, a preservação dos laços com o Mediterrâneo oriental e meridional e a persistência do Direito Romano. Ademais, é pelo Mediterrâneo que chega aos reinos setentrionais da Europa o conhecimento da filosofia e dos textos científicos gregos, por meio de cópias e traduções dos comentadores árabes. Na península, os reis e os grupos dirigentes favoreceram desde cedo o ensino e os conhecimentos, dos quais podemos citar as grandes figuras da Espanha visigótica, depois as escolas de tradutores dos séculos XII e XIII, a criação das universidades, as disputas teológicas com os doutores judaicos, os canonistas do século XIII, os cosmógrafos e humanistas do século XV. (Rucquoi, 1995, p.15-16)

Com a queda da dinastia de Borgonha, a partir do reinado de D. João I sobe a dinastia de Avis (1385-1580), fortemente comprometida com a classe mercantil e comercial, respondendo com o estímulo ao comércio. D João, interessado no comércio de especiarias, cria condições para as expedições que acontecerão pouco depois, as quais movimentarão rotas terrestres e

\footnotetext{
${ }^{5}$ Baldassare Castiglione (1478 - 1529), diplomata, poema e escritor italiano da alta renascença.

${ }^{6}$ Públio Virgílio Maro (70 a.C - 19 a.C), foi um poeta clássico romano, autor de grandes obras da literatura latina.

${ }^{7}$ Públio Ovídio Naso (43 a.C - 17 ou 18 d.C), foi um poema romano.

${ }^{8}$ Públio Terêncio Afro (185 a.C - 159 a.C), foi um dramaturgo e poeta romano.

${ }^{9}$ Marco Túlio Cícero (106 a.C - 43 a.C), foi um advogado, escritor, orador, filósofo e político da República Romana.

${ }^{10}$ Anício Mânlio Torquato Severino Boécio (480 - 524), filósofo e teólogo romano grande influenciador do pensamento cristão medieval.

${ }^{11}$ Lucio Célio Firmiano Lactâncio (250 - 325) foi um escritor, filósofo, poeta e historiador, também conselheiro de Constantino I, o primeiro imperador romano cristão.

${ }^{12}$ Lúcio Aneu Sêneca (4 a.C - 65) foi um filósofo, advogado e intelectual do Império Romano, adepto ao estoicismo.

${ }^{13}$ Quinto Horácio Flaco (65 a.C - 8 a.C) foi um filósofo e poeta lírico e satírico romano.
} 
marítimas na Europa, onde a Itália, por exemplo, se lançava há mais de duzentos anos no Oriente e no mar do Norte. O rei rodeou-se de legistas emergidos das classes médias, confiou diversas tarefas administrativas aos habitantes das cidades e nomeou o cronista Fernão Lopes ${ }^{14}$ para a missão de legitimar a nova dinastia guardando os arquivos reais. (Ruqcuoi, 1996, p. 197-198). Portugal estava a um passo da expansão marítima.

A centralização precoce do Estado português demonstra uma autoridade e uma dinâmica social e econômica fundamentais para o projeto ultramarino. A Revolução de Avis afirmou uma relação muito forte entre uma nobreza de segunda classe e o Estado, em que a classe mercantil aliada com o Estado português, burguesia portuguesa, negociantes e investidores de outras regiões da Europa patrocinarão mais adiante, a expansão marítima com a busca de novas rotas e especiarias. A corte de Avis representou, em Portugal, a abertura para uma nova era, caracterizada por um enorme interesse na formação do cidadão, inspirados nos primeiros humanistas italianos.

Podemos compreender a grosso modo que, Portugal, vivenciou o Renascimento por meio do contato com os mercadores italianos e, principalmente, da influência dos escritos e ideias, oriundos de viagens e intercâmbios culturais, que permeavam a corte portuguesa. O comércio com a França, Espanha e a Inglaterra eram contínuos, como consequência, a relação comercial e cultural tornou-se intensa. (Dourado \& Pereira)

No decorrer da primeira metade do século XV, a vida política de Portugal obteve influência dos interesses do terceiro filho de D. João I, o infante D. Henrique (1394-1460). Conhecido como “o navegador”, o infante rodeou-se de especialistas do mar, geógrafos, cosmógrafos, matemáticos, astrólogos, e mercadores italianos. Mediante seu amparo, as técnicas de navegação e construção naval fizeram progresso. Sendo considerado um dos príncipes da Renascença (Ruqcuoi, 1996), seus objetivos precisos incluíam a reconquista das terras muçulmanas a favor da cristandade, a política tradicional de controle da passagem entre o Mediterrâneo e o Atlântico e o desejo de fazer crescer a riqueza em Portugal.

A corte de Avis representou a abertura para uma nova era, caracterizada por um enorme interesse na formação do cidadão. Inspirados nos primeiros humanistas italianos, os mentores da educação aristocrática lusitana do período, empenharamse na vida pública de suas cidades e na formação integral dos seus concidadãos. São eles que incentivam um trabalho extenso de traduções do latim, abarcando obras clássicas especialmente de Cícero e Sêneca, de tratados de arte militar e panegíricos imperiais. A primeira tradução integral feita em Portugal na Idade Média de uma obra clássica sem relação com a Igreja está na declaração redigida por volta de 1433-1438 do infante D. Pedro na sua versão do Livro dos ofícios de Marco Tullio Cicero ${ }^{15}$, que é um indício da preocupação de Portugal em se igualar, com a expansão ultramar, com os grandes centros europeus. (Soares, 2014)

Segundo Nair de Nazaré Castro Soares, a interpretação humanista se manifestará na confluência da tradição retórica e da tradição patrística. Juntamente desse humanismo inicial da corte de Avis, afirma-se o gosto pelos romances de cavalaria, pelos tratados de educação de príncipes e por uma produção historiográfica, nas quais as ações de figuras individuais de reis e senhores servirão de paradigmas e exemplo. (Soares, 2014, p.12)

Conforme Soares (2014), a então famosa obra de caráter pedagógico Sobre os nobres costumes e os estudos liberais da juventude (do ano de 1402), bastante difundida na Europa, do humanista italiano Pier Paolo Vergerio (1370-1444), foi traduzida, a pedido do infante D. Pedro (1392- 1449), por Vasco Fernandes de Lucena. A obra almejava a formação do carácter sobre a aquisição cumulativa de conhecimentos, um verdadeiro lema da educação moderna que, de forma geral, teve grande influência na cultura portuguesa e, particularmente, na orientação humanística da dinastia de Avis. Vasco Fernandes de Lucena foi um dos mais ativos tradutores dos autores clássicos que, a serviço dos príncipes de Avis, traduziu também os tratados de Cícero e o

\footnotetext{
${ }^{14}$ Fernão Lopes (1418-1459) foi escrivão e cronista oficial do reino de Portugal.

15 Informação retirada no link: http://www.scrinium.pt/pt/pt-001, pertencente ao Scrinium, base de dados que reúne informações sobre traduções portuguesas remanescentes de textos, sobretudo laicos, escritos em latim durante a Idade Média e início do Renascimento.
} 
Panegírico de Trajano de Plínio, o Moço ${ }^{16}$, obras que difundem o ideal de orador e de homem de Estado. (Soares, 2014, p.1011)

No que toca à Universidade portuguesa, fruto das concepções científicas medievais, esta sustentou, desde a fundação por D. Dinis até o século XV, a mesma estrutura e mesmo plano de estudos. Já com o infante D. Henrique (1394-1460), adquiriu instalações próprias e reestruturação de seu plano curricular com o ensino integral das sete artes liberais, contemplando assim o estudo científico e a observação da natureza, saberes fundamentais para impulso dos Descobrimentos. Os Estatutos Manuelinos reafirmam, em 1508, a estrutura do curso de Artes sem a Retórica, apenas se referindo à Gramática e à Lógica. (Soares, 2014, p.13)

A abertura ao movimento humanista e aos novos métodos ocorreu com certa resistência da instituição universitária. Foi sobretudo na corte e dentro do patrocínio dos reis ao ensino dos nobres que, tanto em Portugal quanto na Espanha, a modernidade no ensino das letras se impôs. Com a Dinastia de Avis, a corte torna-se o grande centro cultural, estimulando a criação literária e a prática da leitura; surgem, também, as primeiras bibliotecas, como as de D. Fernando e D. Duarte. (Soares, 2014, p.13)

De acordo com o historiador José Vitorino de Pina Martins, a renovação prenunciadora do humanismo em Portugal se anunciava pelas obras dos príncipes de Avis, desde D. João I e D. Duarte até o infante D. Pedro. E, por uma forma de caráter específico do Renascimento português, entende-se a preparação rigorosa dos instrumentos técnicos voltados para as grandes navegações. (Martins, 1997, p.179-180)

Conforme Pina Martins, nos livros da autoria de príncipes da dinastia de Avis circulava um fôlego de classicismo, de atenção aos maiores nomes da cultura moderna nos seus primórdios. Todavia, a presença nas livrarias eclesiásticas da primeira metade do Quattrocento é predominantemente de textos bíblicos, teológicos e religiosos, sendo os jurídicos os únicos textos profanos. Na livraria de D. Duarte encontravam-se obras em latim e em língua vulgar, assim como obras de pensamento moralizante, como Valério Máximo ${ }^{17}$, as epístolas de Sêneca, o De officiis de Cícero, os comentários de César ${ }^{18}$, e numerosos outros escritos de ordem patrística, cavaleiresca e religiosa. Na livraria reconstituída do rei D. Afonso V, encontrava-se Dante, textos poéticos e jurídicos de Cino de Pistoia ${ }^{19}$, Guido Guinizeliii ${ }^{20}$ e o Livro das Maravilhas de Marco Polo ${ }^{21}$. Na lista bibliográfica referente à corte de D. Dinis, acrescentava-se textos literários e poéticos, juntamente de romances e nobiliários. (Martins, 1997, 186-187)

Substancialmente, a partir do primeiro Humanismo em Portugal, assim como no restante da Europa, o processo formativo do indivíduo e a sua educação integral, privilegiava como elemento indispensável a capacidade oratória, a arte da palavra do homem na cidade, que se distingue pela cultura, pelo trato e gostos elegantes: a retórica. Soares salienta a grande influência neste ponto de Giovanni Pontano 22 (1426-153). (Soares, 2014, p.30)

A retórica da corte, em seus âmbitos pedagógicos, civis, literários e artísticos, expressa a singularidade do primeiro Humanismo Português, manifestando um ideal de realização plena do ser humano, característico da educação moderna, que se

\footnotetext{
${ }^{16}$ Caio Plínio Cecílio Segundo, ou Plínio, o Moço (61-114), foi orador, jurista e político de nacionalidade romana.

${ }^{17}$ Públio Valério Máximo, foi um escritor romano.

${ }^{18}$ Caio Júlio César (100 a.C - 44 a.C), líder militar e político romano.

${ }^{19}$ Cino de Pistoia (1270 - 1336), poeta e jurista italiano

${ }^{20}$ Guido Guinizelii (1230 - 1276), poeta italiano.

${ }^{21}$ Marco Polo (1254 -1324) foi um embaixador, mercador e explorador veneziano, famoso por viagens até a Ásia.

22 Os textos de Pontano são inaugurais na reflexão europeia sobre a força civilizadora da palavra e a arte da conversação como fenômeno ético e estético. Propõe o autor o ideal de homem urbano e cortesão, instruído e agradável, apontando como estratégia o paciente trabalho de reeducação civil, por meio da prática dos valores da cultura humanística. Tal discurso pedagógico vai além da esfera privada e a personalidade individual, seu alcance objetiva dar regras de conduta à sociedade aristocrática, transformando o cavaleiro feudal no cavalheiro moderno. (Soares, 2014, p.30)
} 
assume como identitário de um povo de vocação universal, ao tempo das Descobertas. O ideal humano irradiado pela Antiguidade greco-latina a partir das sínteses de Cícero, Quintiliano ${ }^{23}$ e Plutarco, ${ }^{24}$ representa um dos aspectos mais salientes do humanismo cívico, fundamento da vida pública, aspecto que permanece desde os humanistas do Quattrocento italiano ao longo de todo Renascimento em Portugal, como essência da mensagem pedagógica e retórica. (Soares, 2014, p.31)

\section{A Tradição dos Espelhos em Portugal e o Livro da Virtuosa Benfeitoria}

O historiador Francisco Antônio de Novaes Campos elenca que, além de Platão e Aristóteles, outros grandes pensadores nutriram a teoria política medieval e renascentista. Entre os gregos, Plutarco é destaque por sua íntima afinidade com o cristianismo. Entre os latinos, ocupam local importante nas citações e traduções, Cícero, Sêneca, Tito Lívio ${ }^{25}$ e Tácito ${ }^{26}$; junto deles os poetas Virgílio, Horácio e Ovídio. Segundo Campos, Xenofonte foi conhecido em Portugal pelo menos desde o início da Dinastia de Avis. A Ciropedia ou Educação de Ciro trouxe, sob a forma de uma biografia romanceada, um dos primeiros tratados sobre a educação do príncipe de que se há conhecimento. Moldado pela prática de uma vida itinerante, o filósofo grego ultrapassa a visão de seus contemporâneos ao conceber o Estado para além dos moldes restritos da cidade, o inserindo no quadro mais lato do império, contribuindo juntamente com os demais autores que tocaram Portugal, para sedimentar um corpus de doutrina política. (Campos, 1985, p.37-38)

O desdobramento do gênero dos Espelhos de Príncipes em Portugal nos mostra as concepções lá presentes, inspiradas na cultura da Antiguidade Clássica, na Bíblia, na Patrística e no Direito Romano. Campos utiliza o domínio dos regimentos dos príncipes para evidenciar, de maneira geral, o estudo da filosofia política em Portugal. Começando pelo Speculum Regum (Espelho dos Reis), primeiro espelho ibérico, de Álvaro Pais, bispo de Silves, escrito entre 1341 e 1344, e destinado ao rei Afonso XI de Castela. (Campos, 1985, p.38-39)

Entre alguns outros tratados do gênero especular, Campos destaca os escritos de Diego Lopes Rebelo, mestre de gramática do Duque de Beja (futuro D. Manuel I), bacharel em Teologia, que editou, por volta de 1496, um tratado intitulado De Depublica Gubernanda per Regem (Do Governo da República pelo Rei). Do posicionamento de Rebelo a respeito das questões controversas sobre a origem e uso do poder real, ecoam o reforço do absolutismo que se processava na época, distinguindo-se em partes de Álvaro Pais. (Campos, 1985, p.39)

Entre o tratado de Álvaro Pais e o de Diogo Lopes Rebelo localizam-se as obras dos príncipes de Avis e o objeto de nossa análise. O Livro da Virtuosa Benfeitoria foi elaborado nos primeiros anos de 1400 por D. Pedro para D. Duarte, e a tradução do De Officiis de Cícero, pelo mesmo príncipe, por volta de 1436. Seguem a estes escritos o Leal Conselheiro de D. Duarte. Campos expõe também o tratado elaborado por Vasco Fernandes de Lucena, a pedido de D. Pedro: Tratado das Virtudes que ao Rei Pertencem, que teria se perdido, além de uma versão da obra de Paulo Vergério: De ingenuis moribus et liberalibus studiis (Instrução de Príncipes). (Campos, 1985, p.40)

O Livro da Virtuosa Benfeitoria, nos apresenta como essa literatura religiosa e doutrinária, composta geralmente por mestres de príncipes e teólogos, que converge com as preocupações educativas de mães, que também elaboram tratados para a educação dos filhos. Dhuoda (800-843), esposa de Bernardo, Marquês de Septimânia, na época carolíngia escreve, entre 841 e 843, para a educação de seu filho Guilherme de 16 anos o Liber manualis, e Cristina de Pisano (1363-1430), filósofa e poetisa

\footnotetext{
${ }^{23}$ Marco Fábio Quintiliano (35 - 96) foi um orador e professor de retórica romano.

${ }^{24}$ Lúcio Méstrio Plutarco (46 - 120) foi um historiador, biógrafo e filósofo influenciado pelo platonismo.

${ }^{25}$ Tito Lívio (59 a.C-17 d.C) foi um filósofo e escritor nascido em Pádua.

${ }^{26}$ Públio Cornélio Tácito ( $\underline{56}$ - ?) foi um senador e historiador romano.
} 
italiana que viveu na França durante primeira metade do século XV, escreve o Livro das três virtudes (1407), traduzido para o português a pedido da rainha D. Isabel, mulher de D. Afonso V e filha do infante D. Pedro. (Soares, 1993, p. 290-304)

Caracterizando o título do Livro da Virtuosa Benfeitoria, expõe o próprio autor, D. Pedro:

[...] spiritual uirtude, que he chamada caridade e amor. Da quall uirtude naçe huu aucto dentro em nos, que sse diz em latim benivolencia, que quer dizer benquerença. E depois deste aueto proçede outro fora de nos, que sse chama em latim benificiençia, e em nossa linguagem, benffeyturia. Sobre esto se funda hua tallrrazom. Toda perssoa que he obrigada pera possuyr algua uirtude, he neçessariamente theuda, a usar de seus auctor segundo requere seu stado e abrange seu poder. E pois nos somos obrigados per precepto pera amar deos e os prouximos mostrasse que lhe deuemos benquerença, da quall se segue o aucto da benffeyturia, de que somos theudos a usar com aquelles que o am mester. (D. Pedro, 1981, p. 577$)^{27}$

Dessa forma, os tratados de educação de príncipes aparecem como as primeiras obras para a formação de leigos, com uma intencionalidade laica e secularizante essencial. Encomendados a imperadores, reis, príncipes e detentores do poder senhorial, para além do elogio e louvor adulatório dos autores, reúnem toda uma ética de funcionalismo laico, com a exalação dos fundamentos e das relações do poder. (Soares, 1993, p. 289-290)

A defesa doutrinária das bases democráticas de um governo monárquico se atrelava a componente ideológica dominante do século XIV, imprimidas nas ideias políticas de autores como Aristóteles, São Tomás de Aquino e Gil de Roma, numa perspectiva de defender a autoridade do estado como fonte de unidade e ordem, possibilitadas pelas dificuldades socioeconômicas de um mundo que se modificava de maneira gradativa, onde o valor estável da terra cede espaço a economia de mercado, gênese da sociedade moderna e capitalista. (Soares, 1993)

A literatura de espelhos de príncipes é difundida em Portugal especialmente por meio das relações constantes entre a corte e os duques de Borgonha. A livraria de Felipe, o Bom ${ }^{28}$, dispunha de autores clássicos como Cícero, Salústio ${ }^{29}$, Tito Lívio, Ovídio, Sêneca, Juvenal, ${ }^{30}$ Valério Máximo, Macróbio ${ }^{31}$, e com diversas traduções em língua vulgar. O duque da Borgonha, com gosto artístico pela iluminura, patrocinou inúmeros artistas, tornando-se o primeiro Mecenas dos Países Baixos, sua corte foi também um centro importante de pintura flamenga. O livro de horas do rei D. Duarte ${ }^{32}$, príncipe de Avis, apresenta reflexos dessa pintura. D. Isabel de Portugal ${ }^{33}$, duquesa de Borgonha e condessa da Flandres, também ficou conhecida pelo seu apresso pelas letras e pelas artes, designada como patronesse of humanism (Padroeira do Humanismo). (Soares, 1993, p.294-295)

Ademais, tais cortes, além da região dos Pirineus, com a casa de Aragão, onde em 1429 D. Pedro se casa com D. Isabel, filha de Jaime II, e a de D. João II de Castela, devido a suas ligações com o reino de Nápoles de Afonso V o Magnânimo, assistirão a um novo eclodir editorial de uma vasta produção literária, que define as origens do humanismo renascentista espanhol:

\footnotetext{
${ }^{27}$ Traduzindo para o português atual: [...] espiritual virtude, que é chamada caridade e amor. Da qual virtude nasce um ato dentro de nós, que se diz em latim benevolência, que quer dizer benquerença. E depois desse ato, procede outro fora de nós, que se chama em latim beneficência, e em nossa linguagem, benfeitoria. Sobre isso se funda sua tal razão. Toda pessoa que é obrigada para possuir alguma virtude, é necessariamente tida, a usar de seus atos, segundo requer seu estado e abrande seu poder. E, pois, nós somos obrigados por preceito para amar Deus, e os próximos mostrarmos que devemos benquerença, da qual se segue o ato da benfeitoria, de que somos tidos a usar com aqueles que é mister.

${ }^{28}$ Filipe III da Borgonha, dito Filipe, o Bom ( $\underline{1396}$ - 1467) foi um príncipe francês da terceira ramificação borgonhesa da Dinastia Capetiana, duque da Borgonha, de Brabante, dentre outros títulos.

${ }^{29}$ Caio Salústio Crispo foi um grande poeta e escritor da literatura latina. Nascido em Amiterno, na Itália, viveu 86 a.C - 35 ac.

${ }^{30}$ Décino Júnio Juvenal (55-127) foi um poeta e retórico romano.

${ }^{31}$ Ambrósio Teodósio Macróbio (370 - 430) foi um escritor, filósofo e filólogo romano.

32 D. Duarte (1391 - 1438), conhecido pelo seu grande interesse pela cultura e pelas letras, foi rei de Portugal e Algarve de 1433 até sua morte.

${ }^{33}$ Isabel de Portugal (1397-1471) foi uma princesa portuguesa da dinastia de Avis, filha única do rei João I de Portugal e sua esposa, Filipa de Lencastre
} 
Significativa é a figura de D. Alonso de Cartagena, tradutor de Cícero, que, por ocasião da sua permanência diplomática em Portugal, entre finais de 1421 e início de 1423, dedica a tradução do De inuentione, inacabada, e um Memoriale virtutum, baseado na Ética de Aristóteles, ao nosso rei D. Duarte. Ou ainda o poeta Juan de Mena, que cultivara um intercâmbio literário e uma amizade dedicada com o Infante D. Pedro. (Soares, 1993, p.294)

Assim sendo, a sociedade portuguesa, estruturada de acordo com um modelo hierárquico eclesiástico, passa por uma renovação nos vários domínios da cultura, na pretensão de garantir e consolidar uma consciência nacional, afirmando às exigências de um mundo civilizado.

Com a renascença das letras, ainda no século XII, e ao longo da Idade Média, de maneira geral, é notória a preocupação com a cultura do príncipe, pois é pelo hábito da leitura que o príncipe medita, aprende, e adquire sabedoria. Sua formação se baseia em pressupostos virtuosos e conhecimentos adequados, providos ora pela Sagrada Escritura, ora por autores clássicos e por demais obras de teor religioso, moral, histórico, político e militar, permeadas de exemplos de reis e filósofos.

A problemática política em Portugal no século XIV surge com mais vigor após a batalha de Aljubarrota ${ }^{34}$, no manifestar do renascimento da cultura antiga. No início do século XV, Portugal gerou, conforme Soares (1993), uma profunda revolução em sua história, renovando a vida pública a começar pela própria dinastia, ascendendo a posições dirigentes pessoas até então obscuras, tomando a nação de uma maior consciência, destruindo aos poucos interesses fortemente enraizados. O desabrochar dessa era vem acompanhado de um maior interesse pela educação e formação da sociedade reformada. Tal inclinação levou os infantes ou o escol intelectual do país a verterem do latim em língua vulgar os autores clássicos. Essas traduções representam um prenúncio do humanismo e o primeiro passo na gradual laicização do estado, facilitada pela nova estrutura social, dada a ascendência de uma nobreza dedicada à causa pública, que concede favores ao povo. Várias linhas de força, junto do laicismo, convergiam para uma evolução do conceito do estado e função do governante, tais como o Direito Romano ${ }^{35}$, o bartolismo ${ }^{36}$ e o aristotelismo político ${ }^{37}$. (Soares, 1993, p.295)

É nesse contexto que se origina o príncipe ideal do Renascimento, com destaque para dois opúsculos de Petrarca ${ }^{38}$, de grande repercussão em Portugal, De republica optime administranda liber e De officio et virtutibus imperatoriis liber, e no que toca ao aspecto pedagógico político, as obas de Pier Paolo Vergério. A influência italiana infere diretamente nos ideais culturais portugueses, ao menos a partir do início do século XIV. A permanência em Itália e em Florença do Infante D. Pedro constitui, inclusive, um marco importante na orientação de seus gostos e definição de seus padrões estéticos, fermentando novas realizações literárias consideradas na corte portuguesa, promovendo uma grande produção literária de viés ético-político, que desempenhou papel importante na consolidação do conceito de Estado e definição de direitos dos governantes e governados. (Soares, 1993, p. 296)

$\mathrm{Na}$ corte de Avis, a leitura de obras que visavam o regimento de príncipes, considerada essencial à formação do governante, presente em grande quantidade na biblioteca do rei D. Duarte, demonstra o programa educativo que os autores empenharam. (Soares, 1993, p. 296-297) Dado tal contexto português, onde coabita tradição e modernidade, conseguimos conceber O livro da Virtuosa benfeitoria como expressão do ambiente em que nasce, espelho da vivência e criação do homem público que foi o Infante D. Pedro.

\footnotetext{
${ }^{34}$ Ocorrida em 1385, consolidou João I como rei de Portugal, o primeiro da Dinastia de Avis.

${ }^{35}$ Norteado pelos princípios básicos da vida, liberdade, propriedade e segurança.

${ }^{36}$ Relacionado ao jurista Bártolo de Sassoferrato, jurista medieval que inseriu o método de interpretação baseado no ratio legis - a razão de ler da lei.

${ }^{37}$ A política essencialmente unida à moral, pois o fim último do estado é a virtude, incluindo a formação moral dos cidadãos e o conjunto dos meios necessários para tal propósito.

${ }^{38}$ Francesco Petrarca (1304 - 1374) foi um intelectual, poeta e humanista italiano.
} 
A vastidão temática que a leitura do primeiro tratado de educação de príncipes português abarca, inclui desde a teorização política subjacente à eloquência e espiritualidade, uma doutrina geral destinada a muitos além do príncipe, como reflexões sobre a condição da realeza e suas responsabilidades a nível institucional, social e econômico, direção espiritual na ascética cristã, condução das almas à perfeição e sua orientação prática. Baseando-se por diversas vezes em autores como Aristóteles, Cícero, Sêneca, o autor usa do método expositivo, influenciado pela escolástica, fazendo uso da lógica da tradição aristotélica medieval, na constante recorrência ao uso de exemplos, na intenção de confirmar e apoiar suas afirmações doutrinais, apresentando também trechos de expressões metafóricas. (Soares, 1993, p.298-299)

Nota-se a influência do pensamento aristotélico:

Todo homem he naturalmente animal acompanhauel. E porem requerem todos de fazer uida em companhia. E porque segundo diz aristotiles em o começo da ensinança politica, quando quer que muytas cousas som hordenadas pera hua fim, conuem delas seia prinçipal guiador que tenha rregimento, nem pode ser acompanhauel uida de muytos, se alguus deles nom sgnardar prinçipalmente o bem da comunydade. Porque segundo a dereyta rrazom, assy como muytas perssoas usam em desuayradas obras, por cobrarem muytas fins, assy conuem que tenha de hua fim a que todallas outras som medianeyramente ordenadas hua soo persoa prinçipal governança. (D. Pedro, 1981, p.593) ${ }^{39}$

E, também, a influência de Sêneca, no que toca o bom entendimento entre o príncipe e seu povo, devendo promover a união entre a comunidade dos súditos e o governante:

Desto Seneca em o primeyro liuro de clemençia, fala prolongadamente, dizendo o prinçipe he atamento per o qual as persoas do poboo som antre sy iuntadas, ele eh muro, em que os sobiecctos som guardados, e spirito peque a multidoo em he defessa, a qual non sendo soportada per consselho de huu principal senhor, ella per suas mesmas forças seria quebrantada, e premuda do seu próprio peso. Em uertude do gouvernador, uiuem os milhares da comunydade, os quaaes sendo desemparados e desacordados da sua cabeça, som feytos preá e rroubo dos seus Imygos. E enquanto o prinçipe os governa per amauyosos e brandos freos, todos teem hua uoontade, e mantendo lealmente a obediençia acreçentam sua fortelleza, per tal maneyra, que aadur podem ser uençidos, nem padecer desauentuyra. E sendo quebrantada e partida em partes desuyradas esta natural liança, ligeralmente pereçerom per desacordo, os que per sua unyom erom temidos, porque em o corpo da comunydade stonçe faz fim o poderyo, quando a obediençia se acaba. (D. Pedro, 1981, p.595) ${ }^{40}$

Para o infante, a excelência do monarca, enquanto cabeça e princípio diretor do corpo político, requer uma reciprocidade de deveres entre governantes e governados, ou seja, entre o príncipe e a comunidade, partindo de princípios virtuosos "Sempre a nobre uoontade traz consigo deseio pera bem fazer prestando a outrem." ${ }^{41}$ (D. Pedro, 1981, p. 576).

A ideia da legitimidade do governo é guiada pela finalidade do bem comum:

[...] assy deue o senhor mais ser amado em o qual toda a comunydade tem sua defenssom e sperança. E porem deue a benquerença ser antre o príncipe e o poboo tam firme que ambos aiam ygyal sentimento de hua desauentura e tomem huu mesmo prazer pollo bem que ouuerem. E pois que huu sem o outro nom pode boo feyto fazer, em tal maneyra se mantenham que o prinçipe consyre que há mester as forças do poboo pera peleiar. E o poboo crea o que he uerdade .s.

\footnotetext{
39 Traduzindo para o português atual: Todo homem é naturalmente animal acompanhável. E, porém, requerem todos de fazer vida em companhia. E porque segundo diz Aristóteles, no começo do ensino político, quando quer que muitas coisas são ordenadas para um fim, convém delas seja principal guiador que tenha regimento, nem pode ser acompanhável vida de muitos, se algum deles não guardar principalmente o bem da comunidade. Porque segundo a direita razão, assim como muitas pessoas usam em desvairadas obras, por cobrarem muitos fins, assim convém que tenha de um fim a que todas outras são medianeiramente ordenadas uma só pessoa principal governança.

${ }^{40}$ Disto, Sêneca em o primeiro livro da Clemência, fala prolongadamente, dizendo o príncipe, é atamento pelo qual as pessoas do povo são antes se juntadas, ele é muro, em que os sujeitos são guardados, e espírito pelo qual a multidão é em defesa, a qual não sendo suportada pelo conselho de um principal senhor, ela por suas mesmas forças seria quebrada, e espremida de seu próprio peso. Em virtude do governador, vivem os milhares da comunidade, os quais sendo desemparados e desacordados da sua cabeça, são feitos preá(?) e roubo dos seus inimigos. E enquanto o príncipe os governa por amaviosos e brandos freios, todos tem sua vontade, e mantendo lealmente a obediência acrescentam sua fortaleza, por tal maneira que não podem ser vencidos, nem padecer desventura. E sendo quebrantada e partida em partes desviradas esta natural aliança, ligeiramente parecerão por desacordo, os que por sua união eram temidos, porque em o corpo da comunidade então faz fim o poderio, quando a obediência acaba.
}

${ }^{41}$ Traduzindo para o português atual: Sempre a nobre vontade traz consigo desejo para bem fazer prestando a outrem. 
que lhe compre prinçipe por sua cabeça, com que possa uençer. E porquanto a uirtude e o bem da comunydade he muyto e apanhado das bondades de muyas perssoas. (D. Pedro, 1981, p.595) ${ }^{42}$

A teoria do benefício permeia os planos ético, econômico e político. A doutrina baseada em Aristóteles e Tomás de Aquino, ao suprir as marcas da vulnerabilidade humana de vertente agostiniana, envolve toda uma concepção de mundo cristã, concepção de valores que inclui o ideal de cavalaria e o império da moral, em que os atos humanos são vistos em sua dimensão humana e eterna. Junto desta perspectiva, predomina no pensamento de D. Pedro uma visão humanista da política, na qual o indivíduo é o principal responsável por suas ações e com ele se determina o desenvolvimento da história e o bem estar da sociedade. Dito isso, é o próprio medievo, mais preocupado nas relações pessoais do homem com Deus, que prenuncia e determina a eclosão do movimento humanista. (Soares, 1993, p.302-308)

Ao par do método dedutivo dos raciocínios de D. Pedro, junto dos inúmeros exemplos recolhidos na Sagrada Escritura, nos autores clássicos e medievais, aparecem também exemplos retirados de sua própria vivência nacional, das variadas formas de comportamento de uma gama de personagens, pertencentes a diferentes estrados sociais, desde o estado eclesiástico, os corregedores, desembargadores, aos mesteirais (artífices) e lavradores. (Soares, 1993, p.304)

A análise crítica feita por D. Pedro de problemas reais de caráter social e político denotam traços humanistas como, por exemplo também, a atenção para a necessidade do rei se fazer acompanhar de bons conselheiros. Tal temática está presente, também, no tratado de seu irmão D. Duarte, o Leal Conselheiro, o Tratado moral de louvores e perigos de alguns estados seculares e das obrigações que neles há com exortação em cada estado de que se trata, de D. Sancho de Noronha e, também, nos conselhos de D. Jerônimo de Osório, em Da instituição real e sua disciplina.

O conceito de verdadeira nobreza presente no Livro da virtuosa benfeitoria, que tece críticas ao ambiente cortesão, sempre propício à intrigas e deslealdades, ao gosto pela vida no palácio e a concentração exagerada de pessoas que nele se abrigam, ao mau desempenho dos cargos públicos, que mais testemunham a ineficácia e arrogância do funcionalismo régio do que prestam serviço à comunidade, à protelação na administração da justiça, a venalidade dos cargos, entre outros, demonstram a afirmação de uma organização do estado que se deveria se apoiar em valores já enunciados. (Soares, 1993, p.304-309)

O tratado de D. Pedro demonstra, também, a preocupação com o infante na boa educação desde a infância, já objetivando um controle da vontade e sua condução para o caminho do bem, ao apoiar-se em exemplos clássicos e bíblicos, ao opor-se à ociosidade e à educação permissiva, nociva à formação da personalidade. $\mathrm{O}$ autor destaca, também, a importância dos bons mestres de formação e de ensino e o cuidado com o excesso de desregramento muitas vezes permitido pelas mães, amas e aias, ao citar exemplos de sua própria infância. (D. Pedro, 1981)

Soares (1993) nos chama atenção para a necessidade de não desligar da temática da educação o significado que assume entre as pessoas o conceito de verdadeira nobreza, o mérito próprio na ascensão social, como prova a presença de letrados e legistas na administração régia, que D. Pedro defende. Se não é possível afirmar o Livro da virtuosa benfeitoria como um plano de educação régia ou aristocrática, é evidente seu intelectualismo socrático, a preocupação com o ensinar, capaz de prover a sabedoria. A crença na natureza humana e sua perfectibilidade, por meio do ensino e da educação, é um dos aspectos presentes da modernidade do seu pensamento. (Soares, 1993, p.309-310)

Para Soares (1993), ao aludir ao exemplo clássico de sabedoria régia de Aristóteles e ao modelo do rei filósofo de Platão, quanto ao projeto educativo no Estado, D. Pedro deixa em seus escritos a necessidade de se tirar o povo da ignorância, sugerindo

\footnotetext{
42 Traduzindo para o português atual: [...] assim deve o senhor mais ser amado no qual toda a comunidade tem sua defesa e esperança. E, porém, deve a benquerença ser entre o príncipe e o povo tão firme que ambos tenham igual sentimento de uma desventura e tomem um mesmo prazer pelo bem que quererem. E, pois, que um sem o outro não pode bom feito fazer, em tal maneira se mantenham que o príncipe consiste que há mister as forças do povo para pelear. E o povo creia que é verdade que lhe cumpre o príncipe por sua cabeça, com que possa vencer. E porquanto a virtude e o bem da comunidade é muito e apanhado das bondades de muitas pessoas.
} 
paulatinamente que o reino, junto dos bispados, ordenassem, criassem colégios. Há indícios, inconclusivos neste ponto, de que o infante estaria pensando em uma educação para todos, assim como defendeu Francesco Patrizi ${ }^{43}$ no Quattrocento italiano.

Num panorama, ainda que geral, podemos perceber a preocupação de D. Pedro em formar um governante nos princípios virtuosos clássicos junto das leis de Deus, ao levar em consideração toda uma tradição eclesiástica, permeada do aristotelismo, e um pré humanismo, que vê a necessidade do bem aconselhar para promover as mudanças necessárias e, antes disso, a prudência para saber bem reger. A bem feitoria deve partir de todos os membros do reino, pois, no dizer do próprio D. Pedro, "Glorioso he o Regno em que o louuor do poboo he testemunha do boõ senhorio, porque sentido os sobiectos per afeyçom leal as necessidades do prinçipe, deseiaram de comprir a sua uoontade." ${ }^{\circ 4}$ (D. Pedro, 1981, p.618)

\section{Considerações Finais}

Ao finalizar este texto, reiteramos que os antecedentes da literatura política portuguesa, como já demarcado, bebem na tradição clássica, na contribuição medieval e na literatura política árabe, presente na Península Ibérica desde o século XIII. A formação do governante pautada nas virtudes propostas desde Álvaro Pais, o auxiliaria a se autogovernar, afastando-se dos vícios, a fim de ser um exemplo para aqueles que governa. A metáfora utilizada em torno do termo espelho, denota aquilo que o rei faz ao observar seu reflexo, sua imagem refletida. Tendo em vista que olhar para o reflexo pode ter o sentido de olhar para dentro de si mesmo, ou ainda, para sua própria alma, tal atitude possibilitaria ao rei se observar por meio do reflexo do espelho e, assim, analisar suas atitudes e corrigir seus erros, ou 'pecados', como entenderiam medievais como Álvaro Pais.

Evidentemente, são séculos que separam e diferenciam os diversos contextos dos Espelhos de Príncipes. No entanto, do ponto de vista histórico e levando em conta a maneira com que se davam as transformações na Idade Média, é interessante observar a influência com que o pensamento humanista irá tocar até mesmo o conservadorismo religioso português, fazendo com que chegue gradualmente à transformação das mentalidades.

Retomado isto, com o exame do Livro da Virtuosa Benfeitoria e, considerando o apanhado do retrospecto do gênero de forma geral, notamos a permanência no ideal de príncipe português, da necessidade de possuir zelo e comprometimento com a fé católica e com a justiça. Para além disto, se faz evidente a preocupação com a tomada de autonomia por parte do indivíduo, enquanto este se reconhece pertencente ao meio, homem político, em sua jornada rumo ao conhecimento e formação. Experiência e saber se entrelaçam na obra do infante D. Pedro, e podemos representar tal pensamento nas palavras de Sêneca, autor tão caro ao pensamento humanista, onde escreve em suas Cartas a Lucílio: "A virtude se reveste de dois aspectos: um, a contemplação da verdade; outro, a acção. O estudo teórico leva-nos à contemplação, a preceptística conduz-nos à acção. Uma acção justa exercita e revela a virtude. ${ }^{\circ 5}$ A virtude é o primeiro passo, mas sua implicação está fundada na vida prática, e tal máxima se faz pertinente para projetar um ideal de príncipe, governante e cidadão. Mais que delinear, essa concepção pode nos levar, por exemplo, a refletir acerca de sua aplicabilidade nos dias atuais, visando possíveis correções e encaminhamentos teóricos metodológicos no campo da formação e educação.

Ao termos em vista que somente conhecendo sua natureza o indivíduo é capaz de aprimorar suas aspirações (autogoverno e conhecimento de $\mathrm{si}^{46}$ ), o mais imprescindível desse conhecimento é o aprendizado de sua utilidade e dependência para com o outro. O mestre, professor, educador, aparece como elemento necessário na perpetuação do saber. É ele que instiga,

\footnotetext{
${ }^{43}$ Francesco Patrizi (1529-15970), foi um filósofo e humanista italiano.

44 Traduzindo para o português atual: Glorioso é o Reino em que o louvor do povo é testemunha do bom senhorio, porque sentindo os sujeitos por afeição leal as necessidades do príncipe, desejarão de cumprir a sua vontade.

${ }^{45}$ In: Segurado \& Campos, J. A. Cartas a Lucílio, Lúcio Aneu Séneca. (Ep. 94, 45)

46 Tema recorrente ao longo da filosofia clássica, presente em autores estoicos e também em Platão.
} 
media e forma os seres sociais, consciente de que é na combinação das especificidades de cada sujeito em particular que se constrói o todo.

O bom governo, na sua capacidade de prover o ambiente necessário, apoiando um sistema educacional que articule o crescimento do indivíduo de maneira consciente, terá como retorno a elaboração e um avanço de uma civilização enriquecida de conhecimento científico aplicado e constantemente aprimorado para sua autopreservação e manutenção. Ainda se pode visar a aquisição de novas técnicas, métodos e descobertas, passíveis essas de modificar cenários sem prejudicar ou excluir os cidadãos, pelo contrário, fazendo-se útil e reconhecida por toda uma sociedade, seja por aqueles que participam diretamente na aquisição, repasse ou contato com o conhecimento, até aqueles indivíduos da população que o percebem materializados na melhoria da qualidade de suas vidas.

\section{Referências}

Bloch, M. (2001). Apologia da história: ou ofício do historiador. Jorge Zahar.

Braudel, F. (1990). História e ciências sociais. (6a ed.), Editorial Presença.

Campos, F. (1985). Príncipe Perfeito: Emblemas de D. João de Solórzano. Instituto de Cultura e Língua Portuguesa.

Costa, R. (2012). A estética do corpo na filosofia e na arte da Idade Média: texto e imagem. Trans/Form/Ação, Marília, 35, 161-178.

Costa, S. S. (2003). Os espelhos de príncipes como padrão para as narrativas biográficas dos reis - O exemplo de D. Álvaro. In: Anais do XXII Simpósio Nacional de História: História, acontecimento e narrativa. João Pessoa: ANPUH.

Dourado, A. V., \& Pereira, A. M. (2020). The history of the jesuit college of São Sebastião do Rio de Janeiro in the 16th century. São Paulo: Research, Society and Development.

D. Pedro. (1981). O livro da Virtuosa Benfeitoria. In: Obras dos Príncipes de Avis. (Introdução e Revisão de M. Lopes de Almeida). Lello \& Irmão.

Diehl, R. M. (2013). O Poder Régio e suas atribuições no Speculum Regum (1341-1344) do franciscano Álvaro Pelayo, bispo de Silves (1333-1350). 2013. (151 p.) Dissertação (Mestrado em História) - Programa de Pós-Graduação em História, Universidade Federal do Paraná, Curitiba, PR.

Ginzburg, C. (1991). Mitos, emblemas, sinais: morfologia e história. Companhia das Letras.

Hahn, F. A. (2006). Reflexos da perfeição: alguns elementos do gênero espelhos de príncipe na Idade Moderna. Varia Scientia, Cascavel, 6(12), $115-157$.

Haroche, C. (1998). Da palavra ao gesto. Editora Papirus.

Japiassú, \&. Marcondes, D. H. (2001). Dicionário Básico de Filosofia. Editora Jorge Zahar.

Le Goff, J. (1994). O Imaginário Medieval. Editora Estampa.

Pereira,A. S. et al. (2018). Metodologia da pesquisa científica. Ed. UAB/NTE/UFSM.

Martins, J. P. (1997). O Humanismo. In: Mattoso, J. (Org.) História da Universidade em Portugal. Coimbra: Universidade de Coimbra, 179 -236.

Rincon, D. L. (2006). Los espejos de príncipes em Castilla (Siglos XIII-XV): Um modelo literário de la realeza bajomedieval. Medievalismo. Madrid (Universidad Complutense), (16), 9-39.

Ruqcuoi, A. (2007). História medieval da península ibérica. Lisboa: Editora Estampa.

Segurado \& Campos, J. A. (2004). Cartas a Lucílio, Lúcio Aneu Séneca. (2a ed.) Fundação Calouste Gulbenkian.

Senellart, M. (2006). As artes de governar. Editora 34.

Skinner, Q. (1999). As fundações do pensamento político moderno. Companhia das Letras.

Soares, N. N. C. (1993). A virtuosa benfeitoria. In: Biblos: Revista da Faculdade de Letras da Universidade de Coimbra. Coimbra, LXIX, $240-314$.

Soares, N. N. C. (2014). O primeiro humanismo ibérico. In: Pontani, I., Miranda, M., \& Manso, H. (Orgs.): Aires Barbosa na Cosmópolis Renascentista. Coimbra: Imprensa da Universidade de Coimbra. 